\title{
Variation for Health-Enhancing Compounds and Traits in Onion (Allium cepa L.) Germplasm
}

\author{
E. Marina Insani1,2\#*, Pablo F. Cavagnaro ${ }^{3,4 \#, ~ V i r g i n i a ~ M . ~ S a l o m o ́ n ' 1, ~ L e a n d r o ~ L a n g m a n 1, ~}$ \\ María Sance $^{3}$, Adriana A. Pazos ${ }^{1}$, Fernando 0. Carrari'2,4 ${ }^{2}$ Olga Filippini' ${ }^{5}$, Laura Vignera ${ }^{5}$, \\ Claudio R. Galmarini ${ }^{3,4,6}$ \\ ${ }^{1}$ INTA, Food Technology Institute, Hurlingham, Argentina \\ ${ }^{2}$ INTA, Biotechnology Institute, Hurlingham, Argentina \\ ${ }^{3}$ Cuyo National University, Mendoza, Argentina \\ ${ }^{4}$ CONICET, Buenos Aires, Argentina \\ ${ }^{5}$ Luján National University, Luján, Argentina \\ ${ }^{6}$ INTA, EEA La Consulta, La Consulta, Argentina \\ Email: "insani.ester@inta.gob.ar
}

Received 23 May 2016; accepted 17 June 2016; published 20 June 20162016

Copyright (C) 2016 by authors and Scientific Research Publishing Inc.

This work is licensed under the Creative Commons Attribution International License (CC BY).

http://creativecommons.org/licenses/by/4.0/

(c) (i) Open Access

\section{Abstract}

Consumption of onion has been associated with reduced incidence of chronic diseases. Phenolic, organosulfur and carbohydrate compounds present are largely responsible for these effects. This study examined compositional variation for health-enhancing compounds in a genetically diverse collection of onion cultivars. Total antioxidant activity and aroma profiles were characterized. Significant variation in bulb concentration for total and individual phenolic compounds, thiosulfinates, carbohydrates, and total and soluble solids was found. The range of variation was particularly large ( $>50$-fold difference between the cultivars with the highest and lowest content) for fructo-oligosaccharides (FOS) and the polyphenols quercetin, epigallocatechin gallate and epicatechin gallate. Amino acid profiles varied significantly as well with substantial variation ( 10 fold) observed in both total and essential amino acids. Total antioxidant activity was positively correlated with polyphenols content, and quercetin in particular $(r=0.83)$, suggesting a major contribution from phenolic compounds to onion antioxidant properties. Significant positive correlation was also found between solids and thiosulfinates content $(r=0.74)$ and between solids and FOS $(r$ $=0.81$ ), suggesting a dilution/concentration effect for organosulfur compounds and FOS in onion bulbs. The present study revealed broad variation for health-enhancing compounds content in

\footnotetext{
\#Both authors contribute equal to this work.

${ }^{*}$ Corresponding author.
}

How to cite this paper: Insani, E.M., Cavagnaro, P.F., Salomón, V.M., Langman, L., Sance, M., Pazos, A.A., Carrari, F.O., Olga Filippini, O., Vignera, L. and Galmarini, C.R. (2016) Variation for Health-Enhancing Compounds and Traits in Onion (Allium cepa L.) Germplasm. Food and Nutrition Sciences, 7, 577-591. http://dx.doi.org/10.4236/fns.2016.77059 
onion germplasm, which can be exploited in breeding programs aiming at increasing onion nutraceutical value.

\title{
Keywords
}

\author{
Onion, Polyphenols, Carbohydrates, Amino Acids, Aroma Profiles
}

\section{Introduction}

Consumption of Allium species, such as onion (A. cepa L.), has been associated with reduced incidence of cardiovascular disease [1] and some types of cancer [2]. These general health-protective effects may be attributed to a few well-demonstrated biological properties of alliums, such as antiplatelet, antioxidant, anti-inflammatory, anti-tumor and hypolipidemic activities [3]. Several Allium compounds, or groups of related compounds, have been recognized as major contributors in exerting these effects.

One source of such phytochemicals is polyphenols. Polyphenols contribute to controlling oxidative stress [4]. Their consumption has been associated with reduced risk of developing some chronic diseases of high prevalence [5]. Immuno-regulatory effects have also been reported [6]. Quercetin is the predominant polyphenol in onion bulbs [7].

Organosulfur compounds (OSC) found in Allium plants have protective effects against cardiovascular disease. Allium OSC have been reported to relieve chronic ailments, such as cancer, diabetes, and cardiovascular disease [8]. Thiosulfinates (TSs) are the major Allium OSC, and they are formed when fresh tissues are crushed allowing the vacuolar enzyme alliinase to interact with cytoplasmic precursors collectively known as ACSOs [for Salk(en)yl-l-cysteine sulfoxides] giving rise to TSs, pyruvate and ammonia (for a comprehensive review on Allium biochemistry see Block [9]). Due to stoichiometric amounts of TSs and pyruvate are produced in the ACSOs-alliinase reaction, pyruvate and TSs contents are positively correlated [10], pyruvate analyses, which are relatively easy to perform, are often used to estimate total TSs or total OSC content [11] [12].

The main carbohydrates in onion bulbs are fructose, glucose, sucrose and low molecular weight fructans [13]. Fructans are polymers of fructose molecules derived from sucrose. Low molecular weight fructans, also known as fruto-oligosaccharides (FOS), are the primary storage carbohydrates in onion bulbs [14]. Onions FOS are an important source of soluble dietary fiber. FOS, along with trans-galactooligosaccharides (TOS), are the only dietary compounds that fulfill the classification criteria for prebiotics [15]. Consumption of prebiotics has been associated with reduced incidence of colon cancer, type-2 diabetes and obesity, modulation of the immune system, amelioration of the clinical manifestations of inflammatory bowel disease and irritable bowel syndrome, and increased calcium absorption and bone mineral density [16].

Free Amino Acids (AAs) play a crucial role in biosynthesis of both structural and functional proteins (i.e., enzymes). In addition, complex roles in various metabolic processes including satiety, gastrointestinal function, glucose homeostasis and cell signaling have been described for free AAs [17]. Thus, AAs profile in foods is a relevant feature with impact on health.

In the plant consumed organs, the type and concentration of different bioactive compounds within each major chemical group will determine the type and intensity of biological activities and the overall value as a functional food.

The present study characterized bulb compositional variation, including many health-enhancing compounds, for polyphenols, OSC, carbohydrates and AAs in a genetically diverse onion collection evaluated during two growing seasons. In addition, Total Antioxidant Activity (TAA) and Aroma Profiles (AP) were determined and associated with the bulb chemical composition. To our knowledge, this study represents the most complete compositional characterization of an onion germplasm collection published to date, in terms of number of bioactive compounds evaluated. Furthermore, relationships among bioactive compounds content and TAA and aroma profiles were investigated and quantified, suggesting an important role for some of these compounds in onion flavor and antioxidant activity. Characterization of these germplasm on the basis of their health-enhancing compounds content will benefit both consumers and onion breeding programs aiming at increasing onion nutraceutical value. 


\section{Materials and Methods}

\subsection{Plant Materials}

Eight onion cultivars developed by the onion breeding program at INTA-Argentina were used (Table 1). Onions were field-grown at the experimental station of INTA La Consulta in two growing seasons referred as "year 1" and "year 2", using a completely randomized design with four replicates. The onion bulbs were obtained from seeds and the crop was established by transplant. Onion bulbs were harvested at vegetative maturity and stored in a cool storage room. The germplasms are named as X-INTA, but hereafter they are mentioned without the word INTA for a more fluent reading.

\subsection{Sample Preparation}

Aqueous extracts from ten unsprouted bulbs per replicate were obtained as follows. The dry outer scales were removed and each bulb was cut in half along the longitudinal axis to obtain a representative sample of outer and inner scales. One half from each of the ten bulbs was combined, weighed, juiced, centrifuged and the clear supernatant was aliquoted and stored at $-80^{\circ} \mathrm{C}$. The other halves were combined and used for determinations of Dry Matter (DM) and Soluble Solids (SS) content. For DM determinations, bulb tissues were crushed, weighted and dried at $50^{\circ} \mathrm{C}$ until constant weight was reached. SS content was measured on an aliquot of fresh onion juice using a hand refractometer.

\subsection{Analysis of Total and Individual Polyphenols}

Total polyphenols (TPs) content was quantified by the Folin-Ciocalteau method of Singleton et al. [18]. Absorbance was measured at $760 \mathrm{~nm}$ in a UV-Vis spectrophotometer (Lambda Bio 20, Perkin Elmer). Results were expressed as mg.gallic Acid Equivalents-GAE-g ${ }^{-1} \mathrm{dw}$ and $\mathrm{mg} \cdot \mathrm{gAE} \cdot \mathrm{g}^{-1} \cdot \mathrm{fw}$.

HPLC analysis of eight individual polyphenols was carried out in an HPLC system (Thermo Separation Products Inc., USA) with an ODS-Hypersil C18 column $(250 \times 4.6 \mathrm{~mm}$, particle size $5 \mu \mathrm{m})$. Compound detection was performed with a fluorescence detector (FL 3000) at 280 (excitation)-310 nm (emission) and a UV-Vis Diode Array Detector (UV 6000 LP) at 280, 306 and $369 \mathrm{~nm}$. The mobile phase used for separation was a linear gradient of $0.1 \%$ trifluoroacetic acid and acetonitrile: $0.1 \%$ trifluoroacetic acid 80:20.

Calibration curves with pure compounds for catechin, epigallocatechin gallate (EGCg), epicatechin gallate (ECg), kaempherol aglicon, quercetin aglicon and myricetin were used as standards (Sigma-Aldrich, St. Louis, USA). Results were expressed as $\mu \mathrm{g} \cdot \mathrm{g}^{-1} \mathrm{fw}$. Quercetin and kaempherol glycosides were evaluated by chemical hydrolysis. Briefly, $0.1 \mathrm{ml}$ of $\mathrm{HCl} 0.25 \mathrm{M}$ was added to $0.9 \mathrm{ml}$ of onion juice in sealed vials and incubated for 2 $\mathrm{h}$ at $100^{\circ} \mathrm{C}$. When samples reached ambient temperature they were filtered through polytetrafluoroethylene (PTFE) membranes (pore diameter $0.45 \mu \mathrm{m}$ ) and analysed by HPLC using the same chromatographic conditions as described above.

Table 1. Morphological and quantitative agronomic characteristics of eight onion cultivars.

\begin{tabular}{|c|c|c|c|c|c|c|c|}
\hline \multirow{2}{*}{ Cultivar } & \multirow{2}{*}{ Bulb color } & \multirow{2}{*}{ Cultivar type $\mathrm{a}^{\mathrm{a}}$} & \multirow{2}{*}{ Market end-purpose } & \multicolumn{2}{|c|}{ Dry matter $\left(\mathrm{g} \cdot \mathrm{kg}^{-1}\right)$} & \multicolumn{2}{|c|}{ Soluble solids $\left(\mathrm{g} \cdot \mathrm{kg}^{-1}\right)$} \\
\hline & & & & Year 1 & Year 2 & Year 1 & Year 2 \\
\hline Valcatorce & yellow & long day & fresh & 104 & 104 & 84 & 87 \\
\hline Cobriza & yellow & long day & fresh & 110 & 115 & 92 & 90 \\
\hline Valuno & yellow & long day & fresh & 96 & 92 & 77 & 80 \\
\hline Angaco & yellow & short day & fresh & 90 & 80 & 81 & 70 \\
\hline Navideña & yellow & intermediate & fresh & 89 & 89 & 81 & 75 \\
\hline Antártica & white & long day & fresh & 164 & 161 & 150 & 145 \\
\hline Ancasti & white & short day & dehydration industry & 174 & 215 & 158 & 201 \\
\hline Refinta20 & white & long day & dehydration industry & 221 & 242 & 216 & 223 \\
\hline
\end{tabular}

${ }^{\mathrm{a} C}$ Classification based on the photoperiod requirements for bulbification (long-, intermediate-and short-day onions require a minimum of 14,13 and 12 hours of day light, respectively). 


\subsection{Total Antioxidant Activity}

Total antioxidant activity (TAA) of bulb samples from year 2 was determined using an ABTS [2,2'-azinobis-(3ethylbenzothiazoline-6-sulfonic acid)] radical cation decolorization assay as described previously [19]. All samples were run twice. Results were expressed as mmoles Trolox equivalents $\mathrm{kg}^{-1} \mathrm{fw}$.

\subsection{Total Thiosulfinates Analysis}

Determinations of pyruvate content, an estimator of Allium's total thiosulfinates (TSs) content were performed according to the method of Schwimmer and Weston [20]. The pyruvate concentration in the juice was calculated based on calibration curves obtained with pyruvate standards. Values were expressed as $\mu$ moles pyruvate $\mathrm{g}^{-1} \mathrm{fw}_{\text {. }}$

\subsection{Carbohydrates}

Carbohydrate analyses by HPLC used the same apparatus as described above for polyphenols, with a Prevail ${ }^{\mathrm{TM}}$ Carbohydrate ES Column $(5 \mu \mathrm{m}, 250 \times 4.6 \mathrm{~mm}$ ) and an Evaporative Light Scattering Detector (ELSD) (Alltech Associates, Inc., Deerfield, USA). For the ELSD, a drift tube temperature of $85^{\circ} \mathrm{C}$, a gas flow rate of 2.2 liters $\min ^{-1}$ and gas pressure of $0.11 \mathrm{MPa}$ were used. High-purity N2 was used as nebulizer gas. Under these conditions, no vaporization of the solute was observed and a stable baseline with attenuation factor of 0.5 was achieved. For compound separation, a linear gradient with a mobile phase of acetonitrile and water was used.

Calibration curves with commercially available standards [Sigma (St. Louis, MO) and Wako Pure Chemical Industries Ltd. (Japan)] for glucose, fructose, sucrose, 1-kestose, nystose and fructo-furanosyl-nystose were used for quantification. In addition, the indirect method of Hoebregs [21] was used for estimation of total oligosaccharides content (for an in-depth analysis of the method used see Prosky and hoebregs [22]) in onion bulbs from year 2.

\subsection{Amino Acid Determinations}

Onion amino acids (AAs) profiles were investigated by ion exchange chromatography (IEC) analysis in bulb samples from year 2. For this, bulb aqueous extracts were acid hydrolyzed in $6 \mathrm{M} \mathrm{HCl}$ for $16 \mathrm{~h}$ at $110^{\circ} \mathrm{C}$ under constant vacuum [23]. After hydrolysis, the $\mathrm{pH}$ of the extracts was adjusted to 2.2. IEC was performed in a Biochrom 30 apparatus (Biochrom Ltd.) equipped with a cationic exchange column. L-Norleucin was used as an internal standard and a solution of eighteen pure amino acid standards was used for identification and quantification.

\subsection{Aroma Profiles}

Onion bulb samples from the year 2 harvest were analyzed using an 'electronic nose' (EN) Alpha Fox 4000 (Alpha MOS ${ }^{\circledR}$, France) with 18 metal oxide sensors (MOS) coupled to an autosampler (HS 100, Alpha MOS ${ }^{\circledR}$, France). In order to obtain the compounds responsible for aroma in equilibrium in the headspace, each sample was incubated at $37^{\circ} \mathrm{C}$ during $150 \mathrm{~s}$ with agitation $(500 \mathrm{rpm})$ prior to the analysis which was performed in duplicate. Data acquisition in the EN was accomplished by injecting $1 \mathrm{ml}$ of headspace at a rate of $1 \mathrm{ml} / \mathrm{s}$. Chromatographic air (N35) was used as carrying gas. The acquisition time per sample was $120 \mathrm{~s}$, with a frequency of 0.5 s. The recovery period between each data acquisition was $20 \mathrm{~min}$.

\subsection{Statistical Analysis}

Treatments were compared by analysis of variance (ANOVA) using the General Linear Model (GLM) procedure as implemented in the IBM SPSS Statistics software package (Chicago, Illinois). Mean comparisons used the Bonferroni or Tukey test. Principal Component Analysis (PCA) was performed to describe the relationship between varieties and variables. Data from aroma profiles were analyzed by means of Discriminant Factorial Analysis (DFA, Alphasoft v8 ${ }^{\circledR}$ ).

\section{Results and Discussion}

\subsection{Dry Matter and Solids Content}

Dry matter (DM) and soluble solids (SS) content varied significantly among the onion cultivars evaluated (Table 1). DM ranged from 80 to $242 \mathrm{~g} \cdot \mathrm{kg}^{-1}$. In average, colored onions had significantly lower DM content (97 
$\mathrm{g} \cdot \mathrm{kg}^{-1}$ ) than white onions (196 g. $\left.\mathrm{kg}^{-1}\right)$. Fresh market onions like Angaco, Navideña and Valuno had the lowest DM content, while Refinta 20 and Ancasti, both cultivars used for dehydration, had the highest DM. SS content varied from $77 \mathrm{~g} \cdot \mathrm{kg}^{-1}$ to $216 \mathrm{~g} \cdot \mathrm{kg}^{-1}$ in year 1 and $70 \mathrm{~g} \cdot \mathrm{kg}^{-1}$ to $223 \mathrm{~g} \cdot \mathrm{kg}^{-1}$ in year 2 . Strong positive correlations were found between DM and SS in year $1(\mathrm{r}=0.99 ; P<0.0001)$ and year $2(\mathrm{r}=1.00 ; P=<0.0001)$. Comparable DM values were reported previously for fresh-market onions (range $85-105 \mathrm{~g} \cdot \mathrm{kg}^{-1}$ ) and two commercial dehydration cultivars (range $=186-194 \mathrm{~g} \cdot \mathrm{kg}^{-1}$ ) from US [24].

\subsection{Polyphenols}

Significant variation $(P<0.05)$ was found for total polyphenols (TPs) and for individual polyphenol compounds among the onion cultivars in both growing seasons (Table 2). TPs content, expressed on dry weight basis, varied more than three-folds, with ranges of 2.26 - 7.94 and 5.98 - $20.22 \mathrm{mg} \cdot \mathrm{gAE} \cdot \mathrm{g}^{-1} \mathrm{dw}$, in year 1 and year 2, respectively. Yellow onion cultivars Valcatorce, Cobriza, and Valuno had the highest TPs content, whereas white bulb cultivars Refinta20, Ancasti and Antartica had the lowest TPs content regardless of year. However, if TPs values were expressed on fresh weight basis, the differences between yellow and white onions were smaller and often not significant (Table 2), suggesting a dilution effect of polyphenols content in yellow onions due to their higher water bulb content, as compared to white onions (Table 1). Presumably, biosynthesis and accumulation of polyphenols in our yellow onion varieties is much higher than in white varieties, but such differences are partly masked — when expressed on fw basis-due to the higher water content in the formers. In agreement with our results, previous studies have also noted significantly higher TPs content in red versus yellow versus white onion varieties [26] [28].

HPLC analysis of individual phenolic compounds revealed the same relative rank among the onion cultivars as observed for TPs (expressed on dw basis) for quercetin (both total quercetin and the aglicon) and myricetin in both growing seasons (Table 2). However, this relative rank was less concordant and highly influenced by yearfor catechins, EGCg and ECg.

Quercetin was the most abundant polyphenol in yellow onions, accounting for $17.1 \%-25.1 \%$ of TPs, whereas its content was much lower in white onions, representing only $0.57 \%-5.8 \%$ of the TPs. The overall variation for total quercetin content among the onion cultivars was 60-fold in year 1 and 13-fold in year 2 (Table 2).

A year effect was observed for catechin, quercetin (total and aglicon), ECg and kaempherol showing, in general, higher content for these compounds in year 1, whereas the opposite trend was observed for TPs and EGCg, for which significantly higher values were obtained in year 2 (Table 2). In addition, several cases of year-toyear variation for particular compounds and cultivars clearly indicate "genotype x year" interactions (e.g., catechins in cv. Cobriza and EGCg in Valcatorce).

Table 2. Bulb content of total and individual polyphenols in eight onion cultivars.

\begin{tabular}{|c|c|c|c|c|c|c|c|c|c|c|c|c|c|c|c|c|c|c|c|c|}
\hline \multirow{2}{*}{$\begin{array}{c}\text { Cultivar } \\
\text { Year }\end{array}$} & \multicolumn{4}{|c|}{ Total Polyphenols (TPs) } & \multicolumn{2}{|c|}{ Catechin } & \multicolumn{2}{|c|}{ EGCg } & \multicolumn{2}{|c|}{ ECg } & \multicolumn{2}{|c|}{$\begin{array}{c}\text { Quercetin } \\
\text { (aglicon) }\end{array}$} & \multicolumn{2}{|c|}{$\begin{array}{c}\text { Total } \\
\text { quercetin }\end{array}$} & \multicolumn{2}{|c|}{$\begin{array}{l}\text { Kaempherol } \\
\text { (aglicon) }\end{array}$} & \multicolumn{2}{|c|}{ Total kaemphero } & \multicolumn{2}{|c|}{ Myricetin } \\
\hline & 1 & 1 & & $2^{*}$ & $1^{*}$ & 2 & 1 & $2^{*}$ & $1^{*}$ & 2 & $1^{*}$ & 2 & $1^{*}$ & 2 & $1^{*}$ & 2 & $1^{*}$ & 2 & 1 & $2^{*}$ \\
\hline Valcatorce & $0.82 \mathrm{ab}$ & $7.94 a$ & $2.09 \mathrm{~b}$ & $20.22 a$ & $0.18 \mathrm{ab}$ & $<0.01 d$ & $0.91 b$ & $0.028 \mathrm{c}$ & $2.19 \mathrm{c}$ & $1.02 \mathrm{a}$ & $2.61 b$ & $1.83 a$ & $17.59 \mathrm{a}$ & $4.88 \mathrm{a}$ & $0.08 \mathrm{~cd}$ & $0.06 b$ & $0.47 \mathrm{~cd}$ & 0.39d & $2.46 \mathrm{a}$ & $3.91 \mathrm{a}$ \\
\hline Cobriza & $0.85 a$ & 7.79a & $2.08 \mathrm{~b}$ & $18.10 \mathrm{ab}$ & $0.22 \mathrm{a}$ & $0.73 a$ & $1.09 \mathrm{ab}$ & $6.96 a$ & $1.35 \mathrm{~d}$ & $0.98 a b$ & $2.63 b$ & $1.85 \mathrm{a}$ & $11.93 b$ & $5.57 \mathrm{a}$ & $0.05 \mathrm{~cd}$ & $0.05 b$ & $0.29 \mathrm{~cd}$ & $0.33 c$ & $0.86 \mathrm{~b}$ & $0.99 b$ \\
\hline Valuno & $0.76 \mathrm{bc}$ & 7.91a & $1.54 \mathrm{c}$ & $16.40 \mathrm{~b}$ & $0.23 a$ & $0.06 \mathrm{bc}$ & $1.26 \mathrm{a}$ & $3.90 \mathrm{~b}$ & $2.20 \mathrm{c}$ & $0.47 \mathrm{~cd}$ & $5.67 a$ & $1.01 \mathrm{~b}$ & $16.71 \mathrm{a}$ & $6.46 \mathrm{a}$ & $0.37 a$ & $0.04 b$ & $1.92 b$ & $0.57 \mathrm{~b}$ & $0.62 b$ & $0.43 c$ \\
\hline Angaco & $0.51 \mathrm{~d}$ & $5.67 \mathrm{~b}$ & $1.49 \mathrm{c}$ & 18.41ab & $0.17 \mathrm{~b}$ & $0.13 b$ & $0.40 \mathrm{~cd}$ & $1.99 \mathrm{bc}$ & $0.96 \mathrm{~d}$ & $1.11 \mathrm{a}$ & $1.74 \mathrm{bc}$ & $0.67 \mathrm{bc}$ & $6.23 c$ & $2.64 \mathrm{~b}$ & $0.20 \mathrm{~b}$ & $<0.01 \mathrm{c}$ & $0.95 c$ & $<0.01$ & $0.44 \mathrm{~b}$ & $0.42 \mathrm{c}$ \\
\hline Navideña & $0.57 \mathrm{~d}$ & $6.42 b$ & $1.54 \mathrm{c}$ & $17.45 \mathrm{ab}$ & $0.14 \mathrm{bc}$ & $0.03 c$ & $0.60 \mathrm{c}$ & $1.96 \mathrm{bc}$ & $1.16 \mathrm{~d}$ & $0.12 \mathrm{~d}$ & $1.10 \mathrm{~cd}$ & $0.46 \mathrm{c}$ & $7.42 \mathrm{c}$ & $2.44 \mathrm{bc}$ & $0.09 \mathrm{c}$ & $0.02 \mathrm{c}$ & $0.42 \mathrm{~cd}$ & $0.19 \mathrm{e}$ & $0.85 \mathrm{~b}$ & $0.32 \mathrm{~cd}$ \\
\hline Antártica & $0.39 \mathrm{e}$ & $3.45 c$ & $1.37 \mathrm{c}$ & $8.48 \mathrm{~d}$ & $0.16 \mathrm{bc}$ & $0.05 c$ & $0.30 \mathrm{~d}$ & $1.61 b c$ & $2.74 \mathrm{~b}$ & $0.56 \mathrm{bc}$ & $0.22 \mathrm{~d}$ & $0.42 \mathrm{c}$ & $0.38 \mathrm{~d}$ & $0.84 \mathrm{~cd}$ & $0.03 \mathrm{~d}$ & $0.02 \mathrm{c}$ & $0.08 \mathrm{~d}$ & $0.23 \mathrm{e}$ & $0.14 \mathrm{~b}$ & $0.21 \mathrm{~d}$ \\
\hline Ancasti & $0.56 \mathrm{~d}$ & $2.26 \mathrm{~d}$ & $2.63 a$ & $12.27 \mathrm{c}$ & $0.09 d$ & $<0.01 d$ & $0.32 \mathrm{~d}$ & $0.28 c$ & $2.24 \mathrm{c}$ & $0.16 \mathrm{~cd}$ & $0.15 \mathrm{~d}$ & $0.04 \mathrm{~d}$ & $0.30 \mathrm{~d}$ & $0.50 \mathrm{~d}$ & $<0.010$ & $<0.01 \mathrm{c}$ & $<0.01 \mathrm{e}$ & $0.72 \mathrm{a}$ & ND & $0.16 \mathrm{~d}$ \\
\hline Refinta20 & $0.73 c$ & $3.32 \mathrm{c}$ & $1.45 c$ & $5.98 \mathrm{~d}$ & $0.12 \mathrm{~cd}$ & $0.08 \mathrm{bc}$ & $0.30 \mathrm{~d}$ & $3.57 \mathrm{~b}$ & $5.91 \mathrm{a}$ & $1.01 \mathrm{a}$ & $0.06 \mathrm{~d}$ & $0.04 d$ & $0.29 \mathrm{~d}$ & $1.80 \mathrm{bcd}$ & $0.02 \mathrm{~d}$ & $0.09 a$ & $2.78 \mathrm{a}$ & $0.55 b$ & $<0.02$ & ND \\
\hline
\end{tabular}

Values are means of four replicates, expressed as $\mathrm{mg} \cdot \mathrm{gAE} \cdot \mathrm{g}^{-1} \mathrm{fw}$ (left column) and $\mathrm{mg} \cdot \mathrm{gAE} \cdot \mathrm{g}^{-1} \mathrm{dw}$ (right column) for TPs, and as $\mu \mathrm{g} \cdot \mathrm{g}^{-1} \mathrm{fw}$ for individual polyphenols. Different letters within a column indicate significant differences $(P<0.05)$ among cultivars. Asterisks ( $\left.{ }^{*}\right)$ denote significantly higher content in year-to-year comparisons for a given compound and all cultivar. 
Analysis of polyphenols by year and bulb color is presented in Table 3. Cultivars with yellow bulbs had significantly higher mean TPs content $\left(12.7 \mathrm{mg} \cdot \mathrm{g}^{-1} \cdot \mathrm{dw}\right)$ than white bulb cultivars $\left(5.9 \mathrm{mg} \cdot \mathrm{g}^{-1} \cdot \mathrm{dw}\right)$ when expressed on dry weight basis (averaged data from years 1 and 2). The average TPs content in yellow onions was more than twice the content in white onions in both growing seasons (Table 3). Regarding individual phenolic compounds, yellow onions consistently had significantly higher levels of quercetin and myricetin than white onions, whereas for the other polyphenols no clear association was found between compound concentration and bulb color.

The present study characterized, for the first time, bulb polyphenols content in a genetically diverse onion collection from Argentina. These open pollinated varieties represent more than 90\% of the total Argentine onion production, of which nearly 35\% is exported to other South American countries. In these germplasm, broad variation was observed for both TPs and individual phenolic compounds. Quercetin, a compound belonging to the flavonol sub-type within flavonoids, was clearly the predominant polyphenol in colored onions, while kaempherol and the flavan-3-ols (another type of flavonoids) EGCg and ECg were the major polyphenols in white onions (Table 3).

TPs values in this onion collection (Table 2) were within the range of values reported previously in most onion germplasms from other geographical origins [25]-[27], but lower than found in one study [28]. For instance, TPs content in ten US onion varieties (eight yellow, one red and one white) ranged from 0.17 to 1.05 $\mathrm{mg} \cdot \mathrm{gAE} \cdot \mathrm{g}^{-1} \mathrm{fw}$ (values are highly comparable to our data from year 1 ), with the red and white varieties inter-ranked with the yellow ones. Another study by Lu et al. [25] evaluated four US onion varieties cultivated in different locations, and found decreasing -and significantly different-TPs content in red $\left(4.28 \mathrm{mg} \cdot \mathrm{gAE} \cdot \mathrm{g}^{-1} \mathrm{fw}\right)$, white $\left(2.69 \mathrm{mg} \cdot \mathrm{gAE} \cdot \mathrm{g}^{-1} \mathrm{fw}\right)$ and yellow $\left(1.64 \mathrm{mg} \cdot \mathrm{gAE} \cdot \mathrm{g}^{-1} \mathrm{fw}\right)$ varieties, with values for yellow and white onions being similar to our year 2 data. However, TPs values from the present study were lower than those reported for three Czech cultivars with mean TPs content of 26.4, 65.2, and $108.3 \mathrm{mg} \cdot \mathrm{gAE} \cdot \mathrm{g}^{-1} \mathrm{dw}$ for white, yellow and red onions, respectively [28].

Variation for total phenolics content among onion varieties with different bulb color, as reported herein and in previous studies, is directly related to the differential accumulation of major colored polyphenols in bulbs of these varieties. While quercetin (a yellow polyphenol) is a major contributor to TPs in yellow and red onions, with usually higher content observed in yellow onions, this compound is present in low quantities in white onion bulbs (Table 2, and [29]). In addition to quercetin, red onions may accumulate large quantities of red/purple anthocyanins contributing to their higher TPs level, whereas anthocyanins occur at low levels-if at all- in yellow onions, and are missing in white ones [30].

Other phenolic compounds present in onion bulbs in relatively low quantities, such as the Flavan-3-ols catechin, EGCg and ECg, were also quantified in this study. While not quantitatively important in yellow onions, these polyphenols represented a substantial proportion of the TPs in white onions (Table 2 and Table 3). Previous studies have reported undetectable [31] or very low content $\left(0.80 \mu \mathrm{g} \cdot \mathrm{EGCg} \cdot \mathrm{g}^{-1} \cdot \mathrm{fw}\right.$ in a sweet onion variety) [32] for these polyphenols. In our onion germplasm the three compounds could be unambiguously detected and quantified in all the varieties.

With the exception of Refinta20 and Ancasti, which are used for dehydration due to their high solids content, the rest of the onion cultivars included in our study are for fresh consumption (Table 1). In addition to the formers, Antartica, the only fresh consumption white onion variety in our collection, also had high solids content. The nearly two-fold difference in the average solids content observed between white and yellow onions generates a concentration/dilution effect when the data are expressed on fresh weight basis. Although the results expressed on a dry weight basis avoid the dilution effect due to differences in bulb water content, which may be

Table 3. Mean polyphenols content by cultivar's bulb color and year.

\begin{tabular}{cccccccccc}
\hline \multirow{2}{*}{ Year } & Bulb color & \multicolumn{2}{c}{ TPs } & Catechin & EGCg & ECg & Total kaempherol & Total quercetin & Myricetin \\
\hline \multirow{2}{*}{1} & yellow & $0.70^{\mathrm{a}}$ & $7.2^{*}$ & $0.19^{*}$ & 0.85 & 1.57 & 0.81 & $12.00^{*}$ & $1.15^{*}$ \\
& white & 0.56 & 3.0 & 0.12 & 0.31 & $3.67^{*}$ & $1.43^{*}$ & 0.32 & 0.13 \\
\multirow{2}{*}{2} & yellow & 1.74 & $18.1^{*}$ & 0.07 & $3.04^{*}$ & 0.77 & 0.37 & $4.50^{*}$ & $0.57^{*}$ \\
& white & 1.81 & 8.9 & 0.06 & 2.00 & 0.37 & 0.50 & 1.00 & 0.18 \\
\hline
\end{tabular}

${ }^{a}$ Mean values were calculated from all the replicates of yellow- and white-bulb onions regardless of cultivar, and expressed as mg.gAE $\mathrm{g}^{-1} \mathrm{fw}$ (left column) and $\mathrm{mg} \cdot \mathrm{gAE} \cdot \mathrm{g}^{-1} \mathrm{dw}$ (right column) for total polyphenols (TPs), and as $\mu \mathrm{g} \mathrm{g}^{-1} \mathrm{fw}$ for individual polyphenols. Asterisks indicate significantly $(P<0.05)$ higher content for comparisons within the same year. 
more informative for the dehydration or pharmaceutical industries (e.g., in order to establish the content of active compounds in dry onion powder), we presented our data on a fresh weight basis, providing direct information for the fresh-onion consumer which is still the largest onion market worldwide.

\subsection{Antioxidant Activity}

Significant variation was found for total antioxidant activity (TAA) among the onion cultivars (Electronic Supplementary Material, Figure 1). A two-fold difference in TAA was observed between the cultivars with highest (Cobriza) and lowest (Ancasti) TAA. Significant strong positive correlation was found between TPs and TAA, and between quercetin content and TAA $(r=0.83 ; P=0.0001)$ suggesting that quercetin is a major contributor to onion antioxidant capacity. Cultivars Valcatorce, Cobriza and Valuno, had the highest TPs, quercetin and TAA values. Together, these three cultivars represent valuable materials for both, the fresh-market end consumer and for using them in breeding programs aiming at developing onion varieties with high nutraceutical value. Our results are in agreement with previous studies reporting strong positive associations between TPs and antioxidant activity in other onion germplasm [25] [27]. Additionally, quercetin, the major contributor to TPs content in yellow and red onions, is considered a potent antioxidant [33].

\subsection{Carbohydrates Content}

Substantial and significant variation was found for total carbohydrates and for fructose, glucose, sucrose and FOS among the onion cultivars (Figure 1). The content of total non-structural carbohydrates, considered as the sum of free fructose, free glucose, sucrose and total FOS, differed significantly among the onion cultivars, with values ranging from 25.5 (in cv. Angaco) to $85.0 \mathrm{mg} \cdot \mathrm{g}^{-1} \mathrm{fw}$ (Antartica) (Figure 1). White onions had in general higher total carbohydrate content than yellow onions and this was mainly due to their strikingly higher FOS levels. The average FOS content in white onions $\left(52.5 \mathrm{mg} \cdot \mathrm{g}^{-1} \mathrm{fw}\right)$ was nearly 8 times higher than the average FOS level in yellow onions $\left(6.7 \mathrm{mg} \cdot \mathrm{g}^{-1} \mathrm{fw}\right)$. Significant and substantial variation was also found for individual FOS compounds 1-kestose, nystose, and fructo-furanosyl-nystose (FFN) (Figure 2). The latter (FFN) was the mayor contributor to the total FOS content in white onions, followed by nystose and 1-kestose. Conversely, yellow onion varieties had little or undetectable quantities of FFN, with 1-kestose being the predominant FOS in all cases.

Further analysis of individual carbohydrates revealed significant variation for concentration of reducing sugars (RS) fructose and glucose, and such variation was associated with the bulb color phenotype. In average, RS accounted for only $13 \%$ of the total carbohydrates present in white onions, with Refinta20 having the lowest RS content (representing $6 \%$ of its total carbohydrates), whereas in yellow onions RS represented $81 \%$ of the total

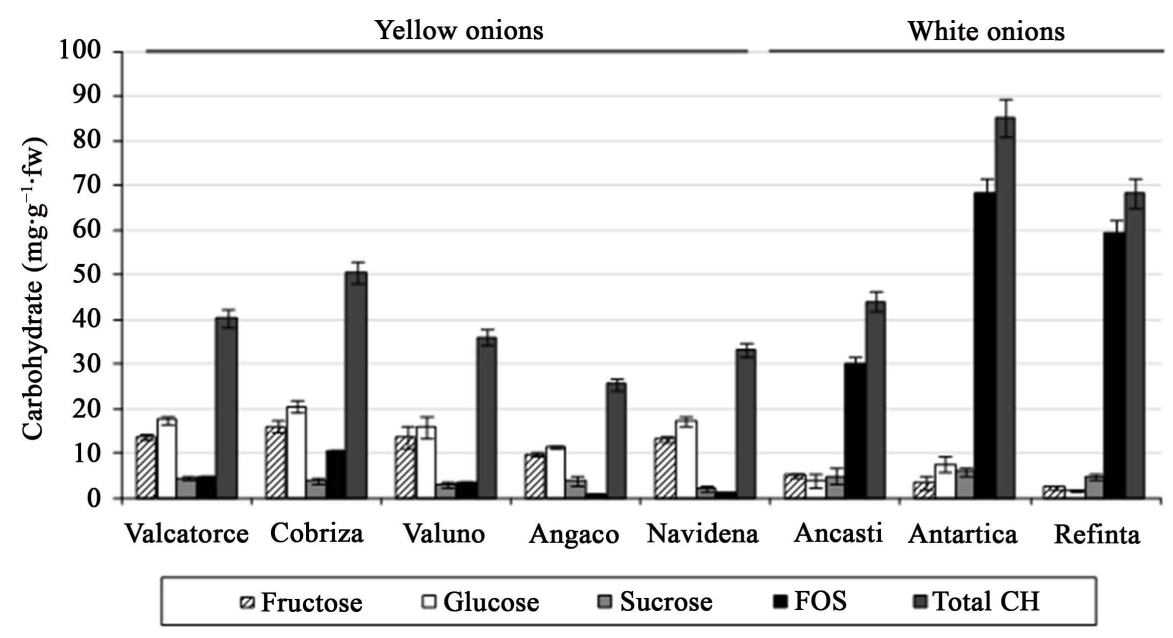

Figure 1. Bulb carbohydrates content in onion cultivars. Values for fructose, glucose, sucrose, FOS, and total non-structural carbohydrates (Total $\mathrm{CH}$ ) are means and SD of four replicates, expressed as $\mathrm{mg} \cdot \mathrm{g}^{-1} \mathrm{fw}$. Total $\mathrm{CH}$ values are the sum of the four individual carbohydrates. The data correspond to onions cultivated in year 2 . 


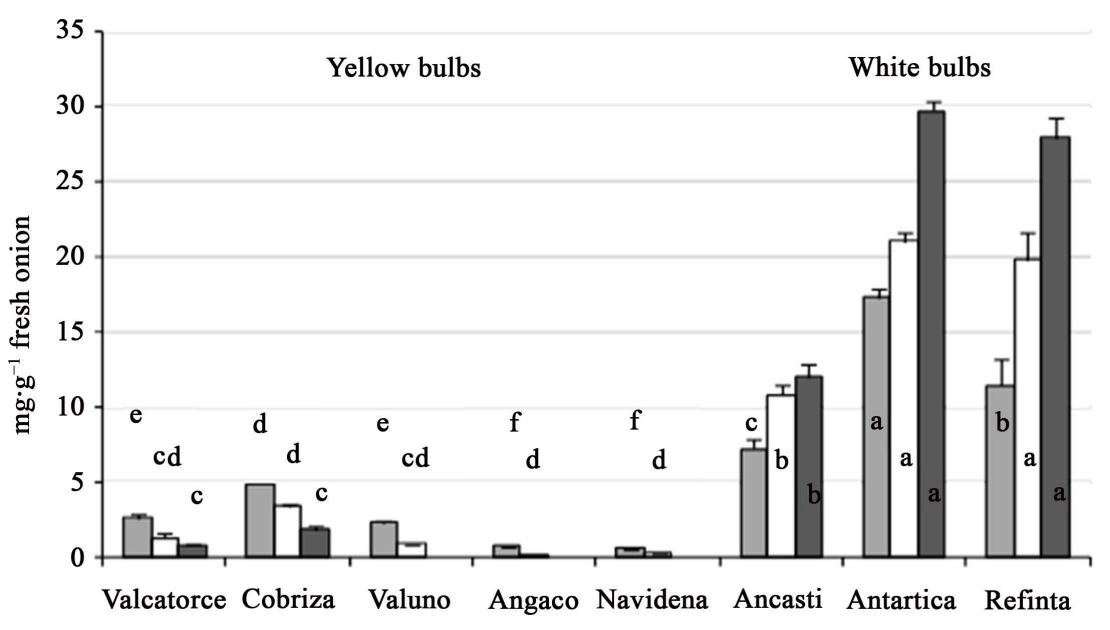

$\square$ 1-Kestose ㅁ Nystose $\square$ FFN

Figure 2. Bulb fructo-oligo-saccharides (FOS) content in onion cultivars. Values for 1-Kestose, Nystose and Fructo-Furanosyl-Nystose (FFN) are means and SD of four replicates, expressed as $\mathrm{mg} \cdot \mathrm{g}^{-1} \mathrm{fw}$, from onions cultivated in year 2 . For each compound, different letters indicate statistical differences $(P<0.05)$ among varieties. FFN was not detected in Valuno, Angaco and Navideña.

carbohydrates, with cv. Cobriza having the highest level of RS. The opposite was observed for sucrose; all the white onions cultivars had higher sucrose content than any yellow cultivar, with a nearly 2-fold difference observed between the mean values for each color class ( $5.8 \pm 1.2 \mathrm{vs.} 3.1 \pm 0.8 \mathrm{mg} \cdot \mathrm{g}^{-1} \mathrm{fw}$ ).

FOS are polymers of fructose. Free fructose-available for polymerization into FOS- mainly derives from cleavage of the disaccharide sucrose, thus releasing glucose and fructose. Because higher sucrose availability positively correlates with higher fructan biosynthesis [34], several authors have suggested that the supply of carbohydrates in the form of sucrose may play a central role in the control of fructan biosynthesis [34] [35]. In line with these reports, we found positive and significant correlation between sucrose and total FOS content $(\mathrm{r}=$ $0.80, P<0.01)$, and between sucrose and individual FOS compounds $(r>0.67, P<0.01)$ for all FOS compounds.

We found broad variation for total FOS content in our onion materials, ranging from 0.8 to $85 \mathrm{mg} \cdot \mathrm{g}^{-1} \mathrm{fw}$, with higher FOS levels generally observed in white onions. A previous study by Jaime et al. [36] reported FOS values for yellow onion cultivars ranging from 23.3 to $141.9 \mathrm{mg} \cdot \mathrm{g}^{-1} \mathrm{dw}$, that are highly comparable with FOS values obtained for yellow onions in the present study [13.8 $-137.1 \mathrm{mg} \cdot \mathrm{g}^{-1} \mathrm{dw}$ (for comparison purposes, values were expressed on dw basis].

The broad variation found for FOS concentration in these onion germplasm provides an opportunity to further investigate the genetic basis underlying FOS biosynthesis and accumulation; for instance by means of developing segregating populations for FOS content and genetically mapping quantitative trait loci (QTL) for this trait. From a breeding and end-consumer point of view, the white onion cultivars evaluated in this study are of interest due to their very high level of total and individual FOS (Figure 1 and Figure 2). FOS content may also be important for onion post-harvest storage, since direct associations were found between bulb fructan content and the length of marketable post-harvest storage, suggesting that estimation of fructan content at harvest time may help predict onion shelf life period [36].

\subsection{Pyruvate Content}

Pyruvate level is a predictor of onion total thiosulfinates content [11] and intensity of the pungency sensory perception [37]. Significant variation was found for pyruvate bulb content (Electronic Supplementary Material Table 1) among the onion cultivars, with values ranging from 3.1 (in cv. Angaco) to 6.9 (in cv. Refinta20) mol pyruvate $^{-1} \mathrm{fw}$ (mean values for year 1 and year 2 harvests). In average, white onions had significantly $(P<0.01)$ higher pyruvate content than yellow onions. Mean pyruvate levels for both harvests in yellow and white onions were 4.19 and $5.62 \mathrm{~mol}$ pyruvate $\mathrm{g}^{-1} \mathrm{fw}$, respectively. Positive and significant correlation was found between 
pyruvate and dry matter content ( $\mathrm{r}=0.71 ; P<0.0001)$, suggesting a dilution/concentration effect due to cultivar differences in bulb water content (Table 1). In agreement with these results, Galmarini et al. [12] reported significant positive phenotypic and genetic correlations between pyruvate levels, DM and onion-induced antiplatelet activity (OIAA) in onion F3 families, which were genetically unrelated to the materials used in our study. Together, these results suggest that the increase in water content associated with low-DM onions may be responsible for diluting solids and organosulfur compounds associated with onion pungency and antiplatelet activity. In addition, they suggest that analyses of DM content, which are relatively simple to perform, can be used effectively for indirectly selecting for onion pungency and OIAA.

\subsection{Amino Acids}

Broad and significant variation was found for total (TAAs) and essential amino acids (EAAs) among the eight onion cultivars (Table 4). An 11-fold and 17-fold difference in concentration between the highest and lowest content was found for TAAs and EAAs, respectively. White onions Refinta20, Ancasti and Antartica had the highest TAAs and EAAs content, while yellow cultivars Valcatorce and Navideña had the lowest. Further analysis of individual AAs indicated that glutamic acid (Glu) and aspartic acid (Asp) were the most abundant nonessential AAs in all varieties, whereas leucine (Leu) and lysine (Lys) predominated as EAAs in all cultivars except Refinta20 and Navideña, with Arginine (Arg) prevailing in the latters (Electronic Supplementary Material Table 2).

AAs composition in foods is of interest due to the various physiological functions in which they are involved, beyond their role as proteins building blocks. AAs are involved in glucose homeostasis, gastrointestinal health, cell signaling and satiety, among others [17]. In addition, some AAs play a role in the development of flavor. For instance, Cysteine (Cys) is the main sulfur supply for most organic sulfur compounds in Allium, including volatile thiosulfinates, therefore contributing to the development of flavor and pungency in these species. We found important differences in bulb Cys content among the onion cultivars (Figure 3). Cys content correlated positively with pyruvate $(r=0.87, P<0.01)$, an estimator of total thiosulfinates content, suggesting that indeed Cys is necessary for the production of organosulfur compounds. In addition, both variables Cys and pyruvate were positively correlated with DM ( $r=0.90$ and $r=0.86, P<0.01$; for Cys and pyruvate, respectively), reflecting the same dilution/concentration effect noted earlier.

Development of flavor in Allium depends on several factors, including the plant's capacity to uptake sulfur from the soil, its reduction to sulfides and the subsequent assimilation into cysteine [38]. Other compounds, such as complex and simple carbohydrates (i.e., sugars), and aromatic and sulphur AAs are also involved in flavor development. Flavor differences among onion cultivars may be explained by several reasons. Cultivars may uptake and accumulate different quantities of sulfur from the soil and/or they may have different efficiencies for incorporating sulfur into cysteine and other flavor precursors (e.g., ACSOs) [39]. Regardless of the specific mechanisms underlying flavor development in Allium, Cys content seems to plays a central role in this process.

Table 4. Total and essential aminoacids in eight onion cultivars.

\begin{tabular}{ccc}
\hline Cultivar & Total aminoacids & Essential aminoacids \\
\hline Valcatorce & $530 \mathrm{f}$ & $94 \mathrm{f}$ \\
Cobriza & $1140 \mathrm{~d}$ & $193 \mathrm{~d}$ \\
Valuno & $1030 \mathrm{e}$ & $212 \mathrm{c}$ \\
Angaco & $1050 \mathrm{e}$ & $187 \mathrm{~d}$ \\
Navideña & $390 \mathrm{~g}$ & $117 \mathrm{e}$ \\
Ancasti & $1590 \mathrm{~b}$ & $243 \mathrm{~b}$ \\
Antartica & $1310 \mathrm{c}$ & $210 \mathrm{c}$ \\
Refinta20 & $4410 \mathrm{a}$ & $1669 \mathrm{a}$
\end{tabular}

Values are means of eight replicates. Results are expressed as $\mathrm{mg} \cdot \mathrm{kg}^{-1} \mathrm{fw}$. Different letters in the same column indicate statistical differences $(P<$ 0.05). 


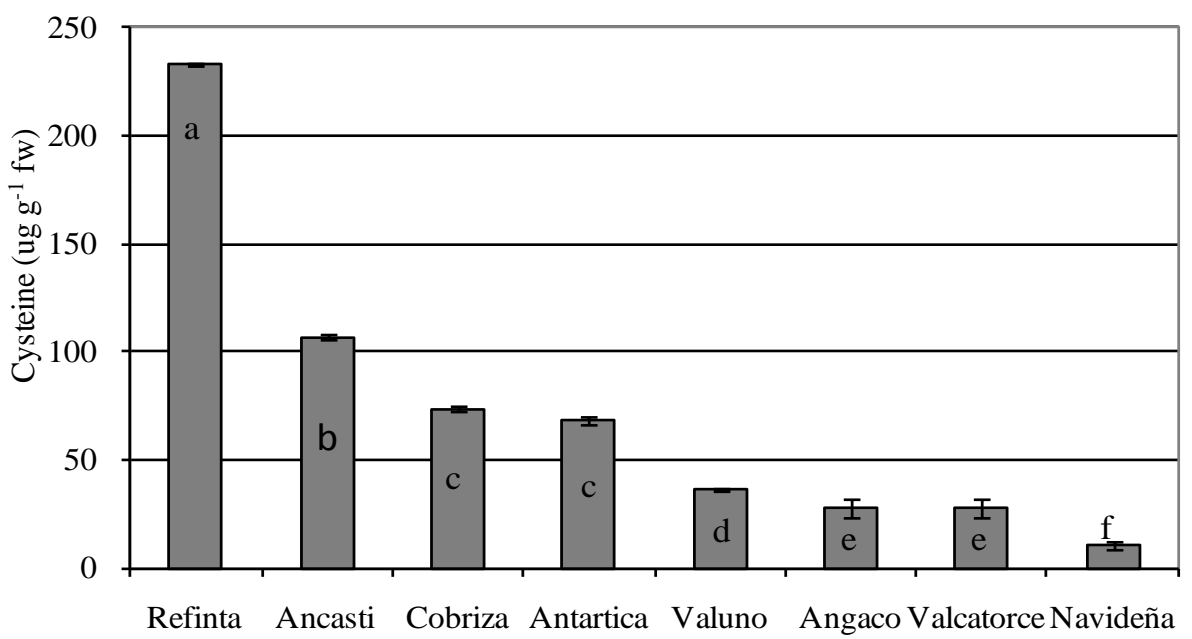

Figure 3. Bulb cysteine content in onion cultivars. Results are means and SD of four replicates. Different letters indicate statistical difference $(P<0.05)$.

\subsection{Aroma Profiles}

Results from aroma profiles (AP) revealed substantial differences among the onion cultivars when analyzed by means of Discriminant Factorial Analysis (DFA) (Figure 4). Two selected components explained nearly 83\% of the total variability. Four distinct groups of cultivars with common aroma profiles could be identified; a group with only white onion cultivars, a second group with three yellow cultivars (Valcatorce, Cobriza and Navidena), and the two remaining groups differentiating samples from the yellow onions Angaco and Valuno.

Significant positive correlation ( $r=0.65, P<0.01$ ) was found between "electronic nose" (EN) data and pyruvate content. The positive correlation between aroma data and pyruvate suggests that volatile thiosulfinates are responsible — to a large extent—of onion aroma and taste. Thiosulfinates have been shown—directly and indirectly - to be responsible for most of garlic and onion antiplatelet properties [11] [40]. Altogether, these results strongly predict that onions with pungent and intense flavor will have higher antiplatelet activity and, thus, higher functional value for the prevention of cardiovascular disease. They also suggest that it will be difficult to develop mild onion cultivars with high antiplatelet activity.

Two previous studies have evaluated onion flavor by means of EN data [41] [42]. These studies examined onion flavor as affected by soil type and nutrient content in a single onion genotype. In the present study, we provide evidence-for the first time- that EN data can effectively be used for discriminating among onions cultivars grown under the same environmental conditions, as well as for characterizing onion germplasm based on their aroma profiles, a relevant trait for fresh onion consumers.

A principal component analysis (PCA) was performed to integrate all the biochemical data from the eight onion cultivars (Figure 5). Positive correlations among variables associated with bioactive compounds (e.g., TPs, FOS and pyruvate) and those related to flavor (e.g., AAs, pyruvate) were found. In agreement with our earlier analysis of aroma profiles, and with previous studies linking pyruvate levels, pungency and antiplatelet activity [12] [13], our PCA results predict that cultivars with intense flavor will have highest functional value. In addition, the concentration/dilution effect observed in onion cultivars due to their differential bulb water content, seems to play an important role in determining the final concentration of both flavor and nutraceutical compounds.

Different target populations demand different health-enhancing foods to match nutritional requirements according to their particular needs. In this context, different onion germplasm may be suitable for this purpose based on their nutraceutical properties. If antioxidant properties are of interest, Cobriza, Valuno and Valcatorce would be the choice of preference for fresh consumption. These cultivars had the highest antioxidant activity and the highest levels of EGCg and quercetin. On the other hand, Refinta20 is a cultivar well suited for dehydration, with high levels of thiosulfinates and FOS as well as with interesting levels of some essential aminoacids (e.g., arginine). 


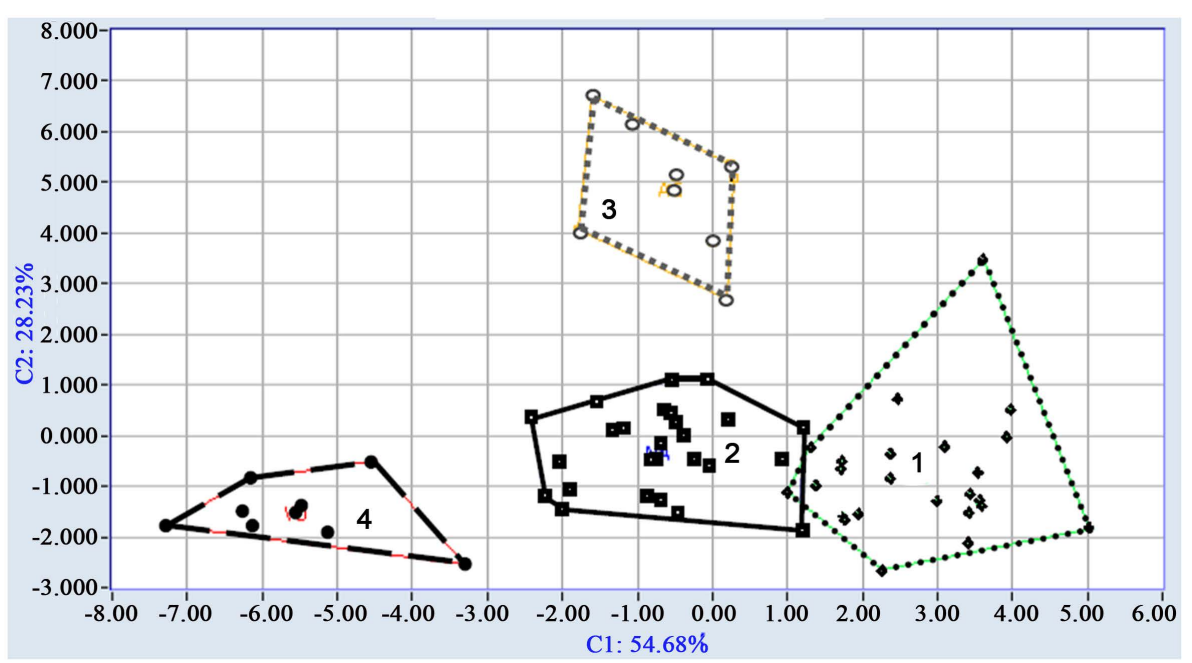

Figure 4. Discriminant Factor Analysis (DFA) of aroma profiles from eight onion cultivars. Four distinct groups of cultivars with common aroma profiles could be identified: group 1 with only white onion cultivars; group 2 with three yellow cultivars (Valcatorce, Cobriza and Navidena); and groups 3 and 4 differentiating samples from the yellow onions Angaco and Valuno. C1 and C2: component 1 and 2 respectively (83\% recognition) constructed with normalized data. The aroma is a good variable to predict group membership.
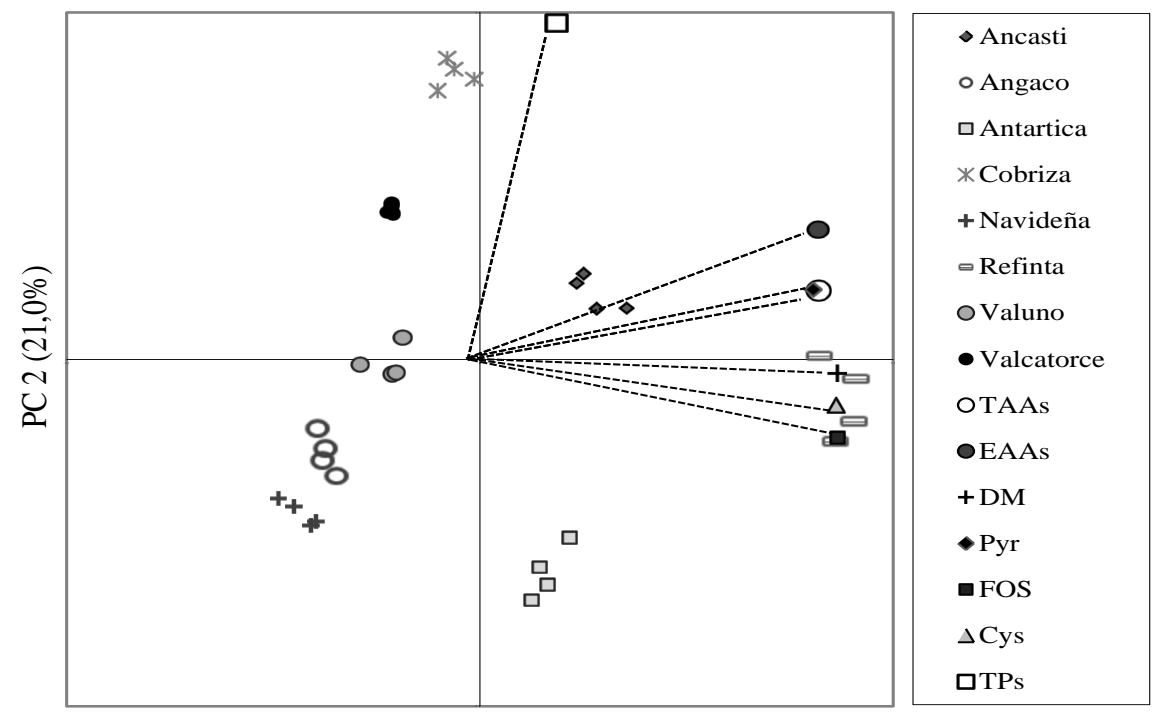

PC $1(70,7 \%)$

Figure 5. Principal component analysis (PCA) of compounds associated with onion flavor and nutraceutical properties. PC1, PC2: principal component $\mathrm{N}^{\circ} 1$ and 2 respectively. In two components 91.7\% of the total variability is explained. TAAs: total aminoacids; EAAs: essential aminoacids; DM: dry mater; Pyr: pyruvate; FOS: fructo-oligosaccharides; Cys: cysteine; TPs: total polyphenols.

\section{Conclusions}

The detailed characterization of these genetically diverse onion germplasm for several health-enhancing compounds will have a positive impact on breeding programs aiming at increasing onion nutraceutical value. For example, the immediate selection of cultivars with high OSC (e.g., Refinta20) and/or high TAA (e.g., Cobriza INTA) can be used as functional food for preventing chronic illnesses, whereas cultivars with high solids and DM content (e.g., Refinta20) are suitable for the dehydration industry. On the other hand, onions with low OSC content and weak aroma profiles (e.g., Angaco INTA) can be used as mild varieties for fresh consumption. 
The broad variation observed for most of the traits suggests that it will be possible to intercross selected genotypes for developing segregating progenies (e.g., F2 families) suitable for genetic mapping of these traits. Such approach would be of great value for detecting markers closely linked to the traits which can be used to assist onion selection and breeding.

The long-day varieties with yellow bulbs Valcatorce INTA, Valuno INTA and Cobriza INTA are rich in phenolic compounds and total antioxidant activity. In contrast, white onion cultivars stand out for their high solids and FOS. By means of analysis of aroma profiles we are able to discriminate between the onion cultivars, and the aroma data correlated with pyruvate content, a predictor of pungency intensity and a strong characteristic for consumers' choices.

The characterization of these cultivars based on their functional compounds content will provide valuable information for the consumer and-because of the widespread use of these materials—will contribute to diversifying onion production and commerce in Argentina and South America.

\section{References}

[1] Banerjee, S.K. and Maulik, S.K. (2002) Effect of Garlic on Cardiovascular Disorders: A Review. Nutrition Journal, 1, 4. http://dx.doi.org/10.1186/1475-2891-1-4

[2] Sengupta, A., Ghosh, S. and Bhattacharjee, S. (2004) Allium Vegetables in Cancer Prevention: An Overview. Asian Pacific Journal of Cancer Prevention, 5, 237-245.

[3] Upadhyay, R.K. (2016) Nutraceutical, Pharmaceutical and Therapeutic Uses of Allium cepa: A Review. International Journal of Green Pharmacy, 10, S46-S64.

[4] Bouayed, J. and Bohn, T. (2010) Exogenous Antioxidants-Double-Edged Swords in Cellular Redox State: Health Beneficial Effects at Physiologic Doses versus Deleterious Effects at High Doses. Oxidative Medicine and Cellular Longevity, 3, 228-237. http://dx.doi.org/10.4161/oxim.3.4.12858

[5] Vauzour, D., Rodriguez-Mateos, A., Corona, G., Oruna-Concha, M.J. and Spencer, J.P.E. (2010) Polyphenols and Human Health: Prevention of Disease and Mechanisms of Action. Nutrients, 2, 1106-1131. http://dx.doi.org/10.3390/nu2111106

[6] Insani, E.M. (2010) Estudio del efecto de la Quercetina, FOS y Allium cepa L. sobre el estado oxidativo e inmunológico en un modelo de inmunodeficiencia secundaria a malnutrición proteica. Ph.D. Dissertation, Buenos Aires University, Buenos Aires.

[7] Mlcek, J., Jurikova, T., Skrovankova, S. and Sochor, J. (2016) Quercetin and Its Anti-Allergic Immune Response. Molecules, 21, 623-637. http://dx.doi.org/10.3390/molecules21050623

[8] Tocmo R., Liang, D., Lin, Y. and Huang, D. (2015) Chemical and Biochemical Mechanisms Underlying the Cardioprotective Roles of Dietary Organopolysulfides. Frontiers in Nutrition, 2, 1-18. http://dx.doi.org/10.3389/fnut.2015.00001

[9] Block, E. (2010) Garlic and Other Alliums: The Lore and the Science. Royal Society of Chemistry, Cambridge.

[10] Cavagnaro, P.F., Camargo, A., Galmarini, C.R. and Simon, P.W. (2007) Effect of Cooking on Garlic (Allium sativum L.) Antiplatelet Activity and Thiosulfinates Content. Journal of Agricultural and Food Chemistry, 55, 1280-1288. http://dx.doi.org/10.1021/jf062587s

[11] Goldman, I.L., Kopelberg, M., Debaene, J.P. and Schwartz, B. (1996) Antiplatelet Activity in Onion (Allium cepa L.) Is Sulfur Dependent. Thrombosis and Haemostasis, 76, 450-452.

[12] Galmarini, C., Goldman, I. and Havey, M. (2001) Genetic Analyses of Correlated Solids, Flavor and Health-Enhancing Traits in Onion (Allium cepa L.). Molecular Genetics and Genomics, 265, 543-551. http://dx.doi.org/10.1007/s004380100445

[13] Abrameto, M.A., Gil, M.I., Pozzo Ardizzi, M.C., Ashckar, G.M., Avilés, L., Van Konijnenburg, A., et al. (2012) Soluble Carbohydrates in Onion Cultivars Stored on Field Conditions in the South West of Negro River, Argentina. Agrociencia Uruguay, 16, 67-73.

[14] Jaime, L., Martínez, F., Martín-Cabrejas, M.A., Molla, E., López-Andreu, F.J., Waldron, K.W. and Esteban, R.M. (2002) Study of Total Fructan and Fructo-Oligosaccharide Content in Different Onion Tissues. Journal of the Science of Food and Agriculture, 81, 177-182. http://dx.doi.org/10.1002/1097-0010(20010115)81:2<177::AID-JSFA796>3.0.CO;2-9

[15] Roberfroid, M. (2007) Prebiotics: The Concept Revisited. The Journal of Nutrition, 137, 830S-837S.

[16] Roberfroid, M., Gibson, G., Hoyles, L., McCartney, A., Rastall, R., Rowland, I., Wolvers, D., Watzl, B., Szajewska, H., Stahl, B., Guarner, F., Respondek, F., Whelan, K., Coxam, V., Davicco, M.J., Léotoing, L., Wittrant, Y., Delzenne, N., 
Cani, P., Neyrinck, A. and Meheust, A. (2010) Prebiotic Effects: Metabolic and Health Benefits. British Journal of Nutrition, 104, S1-S63. http://dx.doi.org/10.1017/S0007114510003363

[17] Millward, D., Layman, D., Tomé, D. and Schaafsma, G. (2008) Protein Quality Assessment: Impact of Expanding Understanding of Protein and Amino Acid Needs for Optimal Health. The American Journal of Clinical Nutrition, 87, 1576S-1581S.

[18] Singleton, V., Orthofer, R. and Lamuela-Raventós, R. (1999) Analysis of Total Phenols and Other Oxidation Substrates and Antioxidants by Means of Folin-Ciocalteu Reagent. Methods in Enzymology, 299, 152-178. http://dx.doi.org/10.1016/S0076-6879(99)99017-1

[19] Re, R., Pellegrini, N., Proteggente, A., Yang, M. and Rice-Evans, C. (1999) Antioxidant Activity Applying and Improved ABTS Radical Cation Decolorization Assay. Free Radical Biology and Medicine, 26, 1231-1237. http://dx.doi.org/10.1016/S0891-5849(98)00315-3

[20] Schwimmer, S. and Weston, W.J. (1961) Onion Flavor and Odor, Enzymatic Development of Pyruvic Acid in Onion as a Measure of Pungency. Journal of Agricultural and Food Chemistry, 9, 301-304. http://dx.doi.org/10.1021/jf60116a018

[21] Hoebregs, H. (1997) Fructans in Foods and Food Products, Ion-Exchange Chromatographic Method: Collaborative Study. Journal of AOAC International, 80, 1029-1037.

[22] Prosky, L. and Hoebregs, H. (1999). Methods to Determine Food Inulin and Oligofructose. The Journal of Nutrition, 129, 1418S-1423S.

[23] Gehrke, C., Wall, L., Absheer, Kaiser, F. and Zumwalt, R. (1985) Sample Preparation for Chromatography of Amino acids: Acid Hydrolisis of Proteins. Journal of AOAC International, 68, 811-821.

[24] Raines, S., Henson, C. and Havey, M. (2009) Genetic Analyses of Soluble Carbohydrate Concentrations in Onion Bulbs. Journal of the American Society for Horticultural Science, 134, 618-623.

[25] Lu, X., Wang, J., Al-Qadiri, H.M., Ross, C.F., Powers, J.R., Tang, J. and Rasco, B.A. (2011) Determination of Total Phenolic Content and Antioxidant Capacity of Onion (Allium cepa) and Shallot (Allium oschaninii) Using Infrared Spectroscopy. Food Chemistry, 129, 637-644. http://dx.doi.org/10.1016/j.foodchem.2011.04.105

[26] Elhassaneen, Y.A. and Sanad, M.I. (2009) Phenolics, Selenium, Vitamin C, Amino Acids and Pungency Levels and Antioxidant Activities of Two Egyptian Onion Varieties. American Journal of Food Technology, 4, 241-254. http://dx.doi.org/10.3923/ajft.2009.241.254

[27] Yang, J., Meyers, K.J., van der Heide, J. and Liu, R.H. (2004) Varietal Differences in Phenolic Content and Antioxidant and Antiproliferative Activities of Onions. Journal of Agricultural and Food Chemistry, 52, 6787-6793. http://dx.doi.org/10.1021/jf0307144

[28] Lachman, J., Proněk, D., Hejtmánková, A., Dudjak, J., Pivec, K. and Faitová, K. (2003) Total Polyphenol and Main Flavonoid Antioxidants in Different Onion (Allium cepa L.) Varieties. Horticultural Science (Prague), 30, 142-147.

[29] Lee, E.J., Patil, B.S. and Yoo, K.S. (2015) Antioxidants of 15 Onions with White, Yellow and Red Colors and Their Relationship with Pungency, Anthocyanin, and Quercetin. LWT_Food Science and Technology, 63, 108-114. http://dx.doi.org/10.1016/j.lwt.2015.03.028

[30] Slimestad, R., Fossen, T. and Vågen, I.M. (2007) Onions: A Source of Unique Dietary Flavonoids. Journal of Agricultural and Food Chemistry, 55, 10067-10080. http://dx.doi.org/10.1021/jf0712503

[31] De Pascual-Teresa, S., Santos-Buelga, C. and Rivas-Gonzalo, J.C. (2000) Quantitative Analysis of Flavan-3-ols in Spanish Foodstuffs and Beverages. Journal of Agricultural and Food Chemistry, 48, 5331-5337. http://dx.doi.org/10.1021/jf000549h

[32] Harnly, J.M., Doherty, R., Beecher, G.R., Holden, J.M., Haytowitz, D.V., Bhagwat, S. and Gebhardt, S. (2006) Flavonoid Content of U.S. Fruits, Vegetables and Nuts. Journal of Agricultural and Food Chemistry, 54, 9966-9977. http://dx.doi.org/10.1021/jf061478a

[33] Erlund, I. (2004) Review of the Flavonoids Quercetin, Hesperetin, and Naringenin. Dietary Sources, Bioactivities, Bioavailability and Epidemiology. Nutrition Research, 24, 851-874. http://dx.doi.org/10.1016/j.nutres.2004.07.005

[34] Pattanagul, W., Miranda, E.R. and Madore, M.A. (2002) Carbohydrate Synthesis and Crop Metabolism. In: Pessarakli, M., Ed., Handbook of Plant and Crop Physiology, CRC Press, Boca Raton, 467-483.

[35] Tognetti, J.A., Pontis, H.G. and Martínez-Noël, G.M.A. (2013) Sucrose Signaling in Plants. Plant Signaling \& Behavior, 8, e23316.

[36] Jaime, L., Martín-Cabrejas, M., Molla, E., López-Andreu, F. and Esteban, R. (2001) Effect of Storage on Fructan and Fructooligosaccharide of Onion (Allium cepa L). Journal of Agricultural and Food Chemistry, 48, 982-988. http://dx.doi.org/10.1021/jf000921t

[37] Kim, H. (2012) Relationships between Consumer Preference, Flavor Attributes and Chemical Compounds of Vidalia 
Onion. Ph.D. Dissertation, Ewha Womans University, Seoul.

[38] Lancaster, J. and Boland, M. (1990) Flavor Biochemistry. In: Rabinowitch, H.D. and Brewster, J.L., Eds., Onions and Allied Crops, CRC Press, Boca Raton, 33-72.

[39] Randle, W. and Bussard, M. (1993) Pungency and Sugars of Short-Day Onions as Affected by Sulfur Nutrition. Journal of the American Society for Horticultural Science, 118, 766-770.

[40] Cavagnaro, P.F. and Galmarini, C.R. (2012) Effect of Processing and Cooking Conditions on Onion (Allium cepa L.) Induced Antiplatelet Activity and Thiosulfinate Content. Journal of Agricultural and Food Chemistry, 60, 8731-8737. http://dx.doi.org/10.1021/jf301793b

[41] Abbey, L., Joyce, D., Aked, J. and Smith, B. (2003) Electronic Nose-Based Discrimination among Spring Onions Grown on Two Different Soils at Three Water-Deficit Stress Levels. ISHS Acta Horticulturae, 600, 479-484. http://dx.doi.org/10.17660/ActaHortic.2003.600.71

[42] Abbey, L., Joyce, D., Aked, J., Smith, B. and Marshall, C. (2005) Electronic Nose Evaluation of Onion Headspace Volatiles and Bulb Quality as Affected by Nitrogen, Sulphur and Soil Type. Annals of Applied Biology, 145, 41-50. http://dx.doi.org/10.1111/j.1744-7348.2004.tb00357.x 


\section{Abbreviations}

AAs: amino acids

AP: aroma profile

EAAs: essential amino acids

ECg: epicatechin gallate

EGCg: epigallocatechin gallate

EN: electronic-nose

FOS: fructo-oligosaccharides

FW: Fresh Weight

GAE: gallic acid equivalents

OSC: organosulfur compounds

TAA: total antioxidant activity

TAAs: total amino acids

TPs: total phenols

TSs: thiosulfinates

Submit or recommend next manuscript to SCIRP and we will provide best service for you:

Accepting pre-submission inquiries through Email, Facebook, Linkedin, Twitter, etc A wide selection of journals (inclusive of 9 subjects, more than 200 journals)

Providing a 24-hour high-quality service

User-friendly online submission system

Fair and swift peer-review system

Efficient typesetting and proofreading procedure

Display of the result of downloads and visits, as well as the number of cited articles

Maximum dissemination of your research work

Submit your manuscript at: http://papersubmission.scirp.org/ 